\title{
Early Mortality Declines at the Dawn of Modern Growth*
}

\author{
Raouf Boucekkine
}

IRES, Université Catholique de Louvain, B-1348 Louvain-la-Neuve, Belgium boucekkine@ires.ucl.ac.be

\section{David de la Croix}

FNRS, Université Catholique de Louvain, B-1348 Louvain-la-Neuve, Belgium delacroix@ires.ucl.ac.be

\section{Omar Licandro}

European University Institute, I-50133 Florence, Italy oman.licandro@iue.it

\begin{abstract}
We explore the hypothesis that demographic changes which began in the seventeenth and eighteenth centuries are at the root of the acceleration in growth rates at the dawn of the modern age. During this period, life tables for Geneva and Venice show a decline in adult mortality; French marriage registers reveal an important increase in literacy; historians measure an acceleration of economic growth. We develop an endogenous growth model with a realistic survival law in which rising longevity increases individual incentives to invest in education and fosters growth. We quantitatively estimate that the observed improvements in adult mortality account for $70 \%$ of the growth acceleration in the pre-industrial age.
\end{abstract}

Keywords: Human capital; longevity; literacy; growth; schooling

JEL classification: $041 ; I 20 ; J 10 ; N 330$

\section{Introduction}

The process of understanding the take-off of traditional societies and their transformation into modern economies is one of the most significant challenges facing economists. An early attempt to build such a dynamic theory

\footnotetext{
* Boucekkine and de la Croix acknowledge financial support from the Belgian French-speaking community (Grant ARC 99/04-235 "Growth and Incentive Design") and the Belgian Federal Government (Grant PAI P5/10, "Equilibrium Theory and Optimization for Public Policy and Industry Regulation"). Licandro acknowledges the financial support of the Spanish Ministry of Sciences and Technology (Grant SEC2000-0260). We thank the participants in seminars at UCLA, Paris, Venice, Rostock and Rorschach, as well as Hypolite d'Albis, Jacques Drèze, Jim Oeppen, and two referees for comments on an earlier version of the paper. 
of production and development was made by Rostow (1960). More recently, Galor and Weil (2000) wonder why output began to grow during the Industrial Revolution, after thousands of years of "Malthusian" stagnation. They stress the link between population dynamics and the economic takeoff. In the same vein, Jones (2001) argues that population density is the key to understanding the Industrial Revolution: once population had reached a critical mass, growth started to accelerate thanks to a more intensive exchange of ideas. In another strand of the literature, authors such as Hansen and Prescott (1998) and Doepke (1999) have modeled this transition by assuming decreasing returns to scale in the agricultural sector (because of land), constant returns to scale in manufacturing and exogenous technological progress. At some point in time, industry became profitable and the transition began.

In this paper, we focus on interesting phenomena that have occurred in Europe prior to and at the dawn of the Industrial Revolution. First, from the end of the seventeenth century, adult mortality started to decline. Second, during the same period, significant improvements in literacy were achieved. Third, growth started to accelerate during the eighteenth century. According to the standard view, the improvements in longevity that Europe has experienced since the eighteenth century are a consequence of enhanced economic conditions. However, many authors argue that the very early decline in mortality should be regarded as exogenous to the economic system. ${ }^{1}$

In accordance with this argument, we explore the hypothesis that improvements in longevity during the seventeenth and eighteenth centuries caused the acceleration in growth rates at the dawn of the modern age. The story we consider goes as follows. Exogenous improvements in adult mortality between 1600 and 1800 increased individual incentives to build human capital. As a consequence, investment in education rose, which exerted a positive effect on economic growth.

To quantitatively assess the effect of improvements in adult mortality on pre-industrial growth, we formulate a model based on de la Croix and Licandro (1999) and Boucekkine, de la Croix and Licandro (2002). The attractive feature of this model is that it embeds a realistic survival law into an endogenous growth model with vintage human capital. It allows us to study how shifts in survival probabilities at different ages affect the incentive to invest in human capital and promote growth.

In this paper, we abstract from two important dimensions of mortality. The first is the gap between the longevity of men and women, which gained

\footnotetext{
${ }^{1}$ See Perrenoud (1985) and Fridlizius (1985). Of course, subsequent improvements in longevity (in the nineteenth and twentieth centuries) were largely due to higher living standard; see Riley (2001).
}

(C) The editors of the Scandinavian Journal of Economics 2003. 
in importance only after the eighteenth century; cf. Vallin (1991). The second is the difference between mortality in cities and in the countryside, which appear to be more important for small children.

Section II outlines the relevant facts about mortality, education and growth in the pre-industrial age. After having assessed that adult longevity increased significantly over the period under study, Section III describes the theoretical model linking education and growth to survival probabilities. In Section IV we quantitatively estimate the shift in the survival law, calibrate the other parameters of the model and compute the effect of rising longevity on education and growth. Section $\mathrm{V}$ concludes.

\section{Selected Facts}

\section{Early Mortality Declines}

To assess the implications of the decline in mortality for the economic takeoff of Western Europe, it is necessary to distinguish the fluctuations in infant mortality from the reduction in the mortality of adults. Infant mortality fluctuates strongly as a function of economic and sanitary conditions, as children are the first to suffer from poor crops and diseases. Child mortality has a major influence on the estimation of life expectancy at birth. Since improvements in infant mortality arose very late in the nineteenth century, it is not surprising that life expectancy at birth shows little trend before that time. Using the data assembled by Wrigley and Schofield (1981) for England, life expectancy at birth peaked in England at 39.5 years of age around the year 1575, dropped to 33 years in the period 1670-1750, and then rose again, reaching its 1575 level in 1820. It then remained steady at 40 years until 1850 . However, this absence of strong improvement before 1850, due to high and volatile infant mortality, hides more subtle improvements with respect to adult mortality. We eliminate the effects of this volatility on life expectancy estimations in order to get a much better picture of the evolution of adult mortality.

To study how adult mortality evolved over time, we need cohort life tables for different periods. We have found two data sets adapted to our purposes. The first is from Perrenoud (1978), who constructed life tables from 1625 to 1825 on the basis of a broad nominative study in Geneva (Switzerland). The second set was compiled by Beltrami (1951). He used parish registers to reconstitute age-group dynamics of the Venetian population over the period 1600-1790. Complete life tables are available for the cohorts born between 1600 and 1700; we only have partial tables for the cohorts born after 1700, since the study ends in 1790. Survival laws are 
normalized to 1,000 at age 10 . This allows us to eliminate the shifts generated by changes in infant mortality and concentrate on the mortality of adults. Figures 1 and 2 display the survival laws of selected cohorts. These data sets are available from the authors on request.

The Geneva picture, Figure 1, displays upward shifts of the curve from one generation to the next. The drop in death rates essentially concerns those aged 40-65. Note that the end of the curve does not move much, reflecting that the gains in longevity do not translate into a rise in the maximum attainable age. Very few persons lived longer than 85.

Figure 2 exhibits the same trend in the data for Venice, compiled from different sources. The lower curve represents the survival law for the generation born in 1600-1610. The dip in the curve at age 30 reflects the dramatic plague experienced by the city in 1630 . The data from this period are thus rather pessimistic regarding longevity, as they take into account the damage caused by these particularly vigorous epidemics. To acquire a more prudent view of the improvement in longevity, we can compare the generation born in 1630-1640 to that born in 1710-1720. There was no plague in Venice during this period (except the one in 1630 that only affected infant mortality in the generation 1630-1640). Here again, the gains in longevity

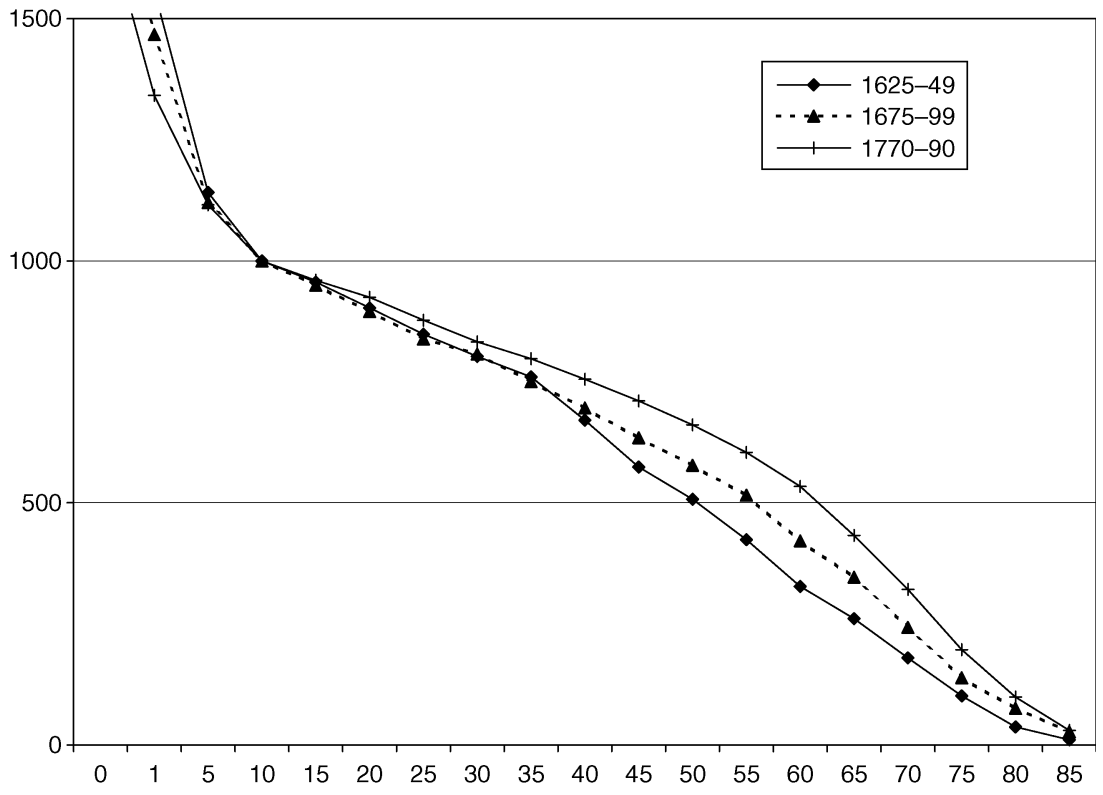

Fig. 1. Survival probabilities-Geneva

(C) The editors of the Scandinavian Journal of Economics 2003. 


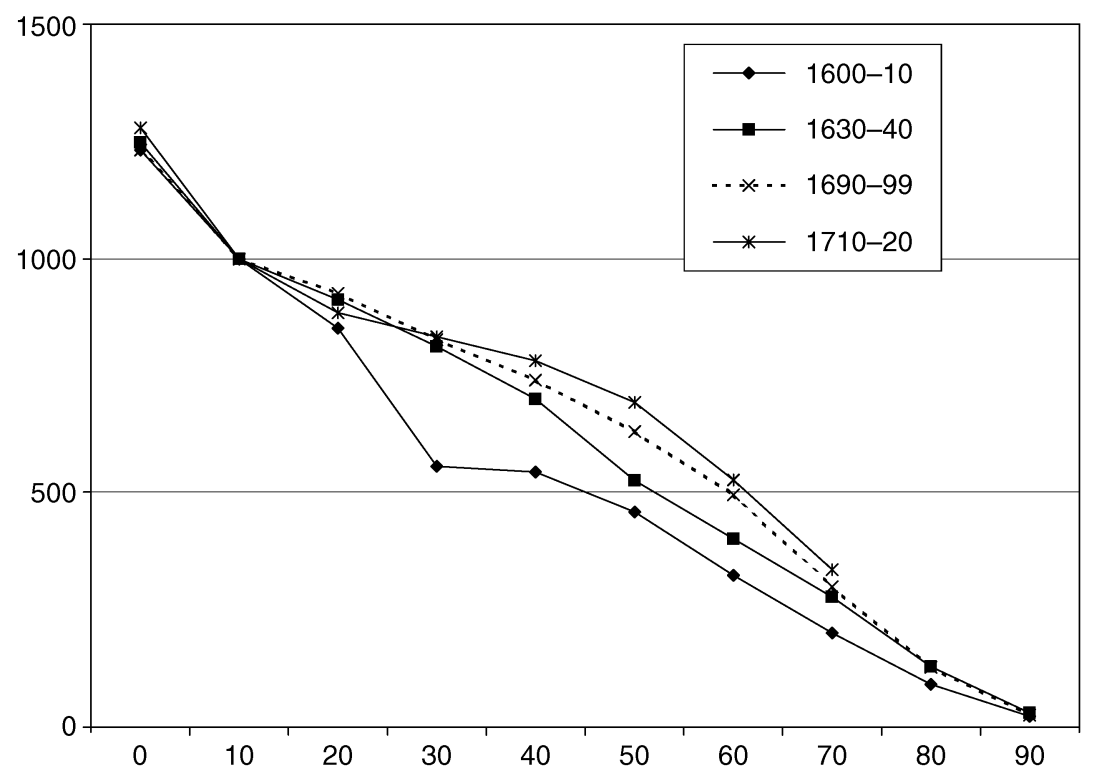

Fig. 2. Survival probabilities-Venice

were concentrated in the working-age population, and life expectancy at 10 increased significantly over the period.

The debate concerning the causes of the initial decline in mortality has not yet been settled. It seems that the classical view, according to which pre-industrial mortality was reduced when nutritional standards were improved, is losing ground. Perrenoud (1985) and Fridlizius (1985) claim that human factors (nutrition, medicine, sanitary conditions and economy) did not play a prominent role in the first phase of the process. Instead, the decline in mortality should be found elsewhere; it can be associated with changes in immunology and/or improvement in the climate.

\section{Improvements in Education}

It is extremely difficult to assess the level of education prevailing before the nineteenth century. Fragmented evidence suggests that illiteracy was a major problem at the beginning of the seventeenth century. For example, and in relation to our data on Venice, Cipolla (1969) reports that: "In 1607 the Venetian government appointed a commission of four naval officers to decide upon the kind of ships to be used in a war against the pirates. They 
must have been officers of quality to be chosen for such a purpose; among the four officers, three of them signed their names with a cross."

There were improvements, however, as witnessed by the French survey undertaken in 1877 by Maggiolo, who asked 15,928 teachers to count the signatures in marriage registers; see Fleury and Valmary (1957). They examined 219,047 documents over the period 1686-1690 and 344,220 documents over $1786-1790$. The global results were that $79 \%$ of newly married people signed with marks in 1686-1690; this percentage dropped to $63 \%$ in 1786-1790. These data are averages for men and women, but we know that men were more literate than women over these periods. For 1786-1790, $52 \%$ of the men and $73 \%$ of the women signed with marks. Similar, but less extensive, data are reported for England and Scotland by Stone (1969). Both data sets suggest that the gains in literacy over the eighteenth century were large.

These gains did not result from the imposition of compulsory schooling systems which were created in Western Europe in the nineteenth century. However, public schools had started to develop earlier. As regards the Geneva example, Cipolla (1969) mentions that a Chinese manuscript from around 1750 reported that the inhabitants of Switzerland "are strong and broad in stature. They are loyal and honest. In each community public schools have been established." Throughout Europe, cities set up schools run by the municipality; see, for example, Schama (1977) on Amsterdam and Rotterdam.

As far as attendance is concerned, some fragmented evidence is available for some local schools or universities. For example, Chartier, Compère and Julia (1976) report the number of students in medicine at Montpellier University over three centuries (1500-1800). The series displays no trend from 1500 to 1730 , then rises until the French Revolution. The number of students doubled between 1720 and 1780 .

The discussion above focuses on formal schooling and literacy. However, human capital was not only formed at schools, whose availability was not necessarily guaranteed, and our model can easily be interpreted as covering other forms of skill accumulation such as apprenticeship. Unfortunately, to our knowledge, there are no time-series data available in this area (number of apprentices, duration of apprenticeship, etc.).

\section{The Acceleration of Growth}

As reported in Table 1, Maddison (1982) estimates a small acceleration of growth during the eighteenth century at the dawn of the First Industrial Revolution. Indeed, the Industrial Revolution started around 1780 in England; see Stokey (2001) and her quantitative model of the British 
Table 1. Growth in Western Europe

\begin{tabular}{lcccc}
\hline & $500-1500$ & $1500-1700$ & $1700-1820$ & $1820-1980$ \\
\hline Population & 0.0 & 0.2 & 0.4 & 0.9 \\
GDP & 0.0 & 0.3 & 0.6 & 2.5 \\
GDP per capita & 0.0 & 0.1 & 0.2 & 1.6 \\
\hline
\end{tabular}

Industrial Revolution. However, since the period 1789-1815 is characterized by wars and civil unrest across Europe, Maddison (2001) retains 1820 as the starting date for the acceleration of growth and technical progress. ${ }^{2}$ The same fact is documented by Marczewski (1961) for France: he estimates that the annual growth rate of total GDP (not per capita) increased from $0.33 \%$ over $1700-1750$ to $1.32 \%$ between 1750 and the French Revolution.

\section{The Model}

To measure the effect of the early gains in life expectancy on education and growth, we use a model adapted from Boucekkine et al. (2002).

\section{Demographic Structure}

Time is continuous and at each point in time there is a continuum of generations indexed by the date at which they were born. Each individual has an uncertain lifetime. The unconditional probability for an individual belonging to cohort $t$ of reaching age $a \in[0, \mathrm{~A}(t)]$, is given by the survival law

$$
m(a, t)=\frac{\alpha(t)-e^{\beta(t) a}}{\alpha(t)-1}
$$

where both functions $\alpha(t)>1$ and $\beta(t)>0$ are continuous. ${ }^{3}$ This twoparameter function is much more realistic than the usual one-parameter function used for example in Kalemli-Ozcan, Ryder and Weil (2000). Like the actual survival laws, it is concave (for $\beta(t)>0$ and $\alpha(t)>1$ ); moreover, it

\footnotetext{
${ }^{2}$ The extent of the pre-industrial acceleration of growth in Western Europe is disputed among economic historians. Clark (2002) finds that labor productivity in agriculture did not grow significantly before 1869. Crafts (1994) concludes that growth of income per head did not move significantly above the long-run pre-industrial average until the second quarter of the nineteenth century.

${ }^{3}$ Indeed, our model is also consistent with piecewise continuous $\alpha(t)$ and $\beta(t)$ functions, allowing for discontinuities in life expectancy.
} 
allows us to model improvements in mortality which do not necessarily affect all ages simultaneously.

The maximum age $\mathrm{A}(t)$ that an individual can reach is

$$
\mathrm{A}(t)=\frac{\log (\alpha(t))}{\beta(t)} .
$$

The unconditional life expectancy associated with (1) is

$$
\Lambda(t)=\int_{t}^{t+\mathrm{A}(t)}(z-t) \frac{\beta(t) e^{-\beta(t)(z-t)}}{\alpha(t)-1} \mathrm{~d} z=\frac{\alpha(t) \log (\alpha(t))}{(\alpha(t)-1) \beta(t)}-\frac{1}{\beta(t)} .
$$

An increase in life expectancy can arise either through a decrease in $\beta$ or an increase in $\alpha$. These two shifts do not lead to the same changes in survival probabilities. When $\alpha$ increases, the improvement in life expectancy relies more on reducing death rates for young and middle-age agents. When $\beta$ decreases, the old agents benefit the most from the drop in death rates, which has an important effect on the maximum age.

Assuming that the initial size of a newborn cohort is $e^{n(t) t}$, with $n(t) \in \mathbb{R}$, its size at time $z>t$ is

$$
e^{n(t) t} m(z-t, t), \quad \text { for } z \in[t, t+\mathrm{A}(t)] .
$$

When the survival law parameters $\alpha(t)$ and $\beta(t)$ are constant, $n(t)$ is also the growth rate of population. Equation (4) reflects that, although each individual is uncertain concerning the time of his death, the measure of each generation declines deterministically over time.

The size of population at time $t$ is given by

$$
P(t)=\int_{t-\overline{\mathrm{A}}(t)}^{t} e^{n(z) z} m(t-z, z) \mathrm{d} z,
$$

where $\overline{\mathrm{A}}(t)$ is the age of the oldest cohort still alive at time $t$, i.e., $\overline{\mathrm{A}}(t)=\mathrm{A}(t-\overline{\mathrm{A}}(t))$.

\section{Production Technology}

There is a unique material good, the price of which is normalized to 1 , that can be used for consumption. The production function is linear in the stock of human capital:

$$
Y(t)=H(t) .
$$

(C) The editors of the Scandinavian Journal of Economics 2003. 
Hence, firms employ the whole labor force to produce as long as the wage per unit of human capital is lower than or equal to one. The equilibrium in the labor market thus implies that the wage per unit of human capital is constant over time and equal to one, i.e., $w(t)=1$, for all $t$. The normalization of human capital productivity to unity does not affect the equilibrium.

\section{The Household's Problem}

An individual born at time $t, \forall t \geqslant 0$, has the following expected utility:

$$
\int_{t}^{t+\mathrm{A}(t)} c(t, z) m(z-t, t) e^{-\theta(z-t)} \mathrm{d} z
$$

where $c(t, z)$ is consumption of a member of generation $t$ at time $z$. The pure time preference parameter is $\theta$.

We assume the existence of complete markets. The intertemporal budget constraint of the agent born at $t$ is:

$$
\int_{t}^{t+\mathrm{A}(t)} c(t, z) R(t, z) \mathrm{d} z=h(t) \int_{t+\mathrm{T}(t)}^{t+\mathrm{A}(t)} R(t, z) \mathrm{d} z .
$$

$R(t, z)$ is the contingent price paid by a member of generation $t$ to receive one unit of the physical good at time $z$ in the case where he is still alive. By definition, $R(t, t)=1$. The LHS is the actual cost of contingent life-cycle consumption. The RHS is the actual value of contingent earnings. The individual enters the labor market at age $\mathrm{T}(t)$ with human capital $h(t)$, and earns a wage $w(z)=1$ per unit of human capital. Human capital accumulation depends on the time spent on education, $T(t)$, and on the average human capital $\bar{H}(t)$ of society at birth:

$$
h(t)=\frac{\mu}{\eta} \bar{H}(t) \mathrm{T}(t)^{\eta},
$$

where $\eta \in[0,1]$ and $\mu \in \mathbb{R}_{+}$are technological parameters. The presence of $\bar{H}(t)$ introduces the typical externality which positively relates the future quality of the agent to the cultural ambience of society (through, for instance, the quality of schooling). This formulation amounts to linking the externality to output per capita, which is another way of reflecting the general quality of a society. The problem of the representative individual of generation $t$ is to select a contingent consumption plan and the duration of his education in order to maximize his expected utility, subject to his 
intertemporal budget constraint, and given the per capita human capital and the sequence of contingent wages and contingent prices. The corresponding first-order necessary conditions for a maximum are

$$
\begin{gathered}
m(z-t, t) e^{-\theta(z-t)}-\lambda(t) R(t, z)=0 \\
\eta \mathrm{T}(t)^{\eta-1} \int_{t+\mathrm{T}(t)}^{t+\mathrm{A}(t)} R(t, z) \mathrm{d} z-\mathrm{T}(t)^{\eta} R(t, t+\mathrm{T}(t))=0,
\end{gathered}
$$

where $\lambda(t)$ is the Lagrangean multiplier associated to the intertemporal budget constraint. Since $R(t, t)=1$ and $m(0, t)=1$, from equation (10) we obtain $\lambda(t)=1$. Using this in (9), we may rewrite contingent prices as

$$
R(t, z)=m(z-t, t) e^{-\theta(z-t)} .
$$

Equation (12) reflects that, with linear utility, contingent prices are just equal to the discount factor in utility, which includes the survival probabilities.

The first-order necessary condition for schooling time is (11). The first term is the marginal gain from increasing the time spent at school and the second is the marginal cost, i.e., the loss in wage income if entry into the job market is delayed.

From (11) and (12) the solution for $\mathrm{T}(t)$ should satisfy:

$$
\mathrm{T}(t) m(\mathrm{~T}(t), t) e^{-\theta \mathrm{T}(t)}=\int_{\mathrm{T}(t)}^{\mathrm{A}(t)} m(a, t) e^{-\theta a} \mathrm{~d} a,
$$

where the RHS represents the discounted flow of wages per unit of human capital.

\section{Aggregate Human Capital}

The productive aggregate stock of human capital is computed from the human capital of all generations currently at work:

$$
H(t)=\int_{t-\overline{\mathrm{A}}(t)}^{t-\overline{\mathrm{T}}(t)} e^{n(z) z} m(t-z, z) h(z) \mathrm{d} z,
$$

where $t-\overline{\mathrm{T}}(t)$ is the last generation that entered the job market at $t$ and $t-\overline{\mathrm{A}}(t)$ is the oldest generation still alive at $t$. Then, $\overline{\mathrm{T}}(t)=\mathrm{T}(t-\overline{\mathrm{T}}(t))$.

(C) The editors of the Scandinavian Journal of Economics 2003. 
The average human capital at the root of the externality (9) is obtained by dividing the aggregate human capital by the size of the population given in (5):

$$
\bar{H}(t)=\frac{H(t)}{P(t)} .
$$

The dynamics of human capital accumulation can be obtained by combining (9) with (14) and (15):

$$
H(t)=\int_{t-\overline{\mathrm{A}}(t)}^{t-\overline{\mathrm{T}}(t)} e^{n(z) z} m(t-z, z) \frac{\mu \mathrm{T}(z)^{\eta} H(z)}{\eta P(z)} \mathrm{d} z .
$$

To evaluate $H(t)$, for $t \geqslant 0$, we need to know initial conditions for $H(t)$, for $t \in[-\overline{\mathrm{A}}(0), 0]$.

\section{The Balanced Growth Path}

Let us define a balanced growth path as a situation where human capital and output grow at a constant rate in a stationary environment. By a stationary environment we refer to $n(t)=n, \alpha(t)=\alpha$ and $\beta(t)=\beta$, for all $t$, which implies that $m(a, t)=m(a)$.

From (13), the stationary solution for $\mathrm{T}$ should satisfy the following condition:

$$
\mathrm{T} m(\mathrm{~T}) e^{-\theta \mathrm{T}}=\int_{\mathrm{T}}^{\mathrm{A}} m(a) e^{-\theta a} \mathrm{~d} a .
$$

From (16), there exists a balanced growth path $H(t)=H e^{\gamma t}$, with $H$ and $\gamma$ both constant, $H$ non-zero, if and only if the following integral equation holds:

$$
\frac{\mu \mathrm{T}^{\eta}}{\eta K} \int_{\mathrm{T}}^{\mathrm{A}} m(z) e^{-\gamma z} \mathrm{~d} z=1 \quad \text { with } \quad K=\int_{0}^{\mathrm{A}} m(a) e^{-n a} \mathrm{~d} a .
$$

As is standard in endogenous growth models, the constant $H$ depends on initial conditions. Under slightly different assumptions, Boucekkine et al. (2002) show that this type of economy has a unique balanced growth path and that the economy converges toward it by oscillations. In the next section, we study the empirical implications of our model, while taking into consideration the contribution of the decline in mortality to launching modern growth. 


\section{Empirical Assessment}

We begin by adapting our model to fit the main facts outlined in Section II.

\section{The Empirical Model}

In order to focus on adult mortality, we disregard the huge swings affecting infant mortality in the seventeenth, eighteenth and early nineteenth centuries. Consistently with our statistical treatment in Section II, where the survival laws from Geneva and Venice data are normalized to 1,000 at age 10, we let the birth date in our model correspond to age 10 in the data. One decision variable is affected by this time shift, the schooling time, $T(t)$. If the birth date is 10 , it can legitimately be argued that the true schooling time is not $T(t)$, but $T(t)+T_{0}$, where $T_{0}$ is the time spent at school before age 10. In our empirical assessment, we take this crucial aspect into account and replace $T(t)$ with $T(t)+T_{0}$ in the model. More precisely, we set $T_{0}=4$, which means that the representative individual has already cumulated four years of education at birth. In the sequel, we study the sensitivity of our results to changes in actual schooling time. With the adaptation described above, the two fundamental equations of the model which give the optimal schooling time and the law of motion of aggregate capital become, respectively:

$$
\begin{gathered}
(\mathrm{T}(t)+4) m(\mathrm{~T}(t), t) e^{-\theta \mathrm{T}(t)}=\int_{\mathrm{T}(t)}^{\mathrm{A}(t)} m(a, t) e^{-\theta a} \mathrm{~d} a \\
H(t)=\int_{t-\overline{\mathrm{A}}(t)}^{t-\overline{\mathrm{T}}(t)} e^{n(z) z} m(t-z, z) \frac{\mu(\mathrm{T}(z)+4)^{\eta} H(z)}{\eta P(z)} \mathrm{d} z .
\end{gathered}
$$

The corresponding steady-state equations are:

$$
\begin{gathered}
(\mathrm{T}+4) m(\mathrm{~T}) e^{-\theta \mathrm{T}}=\int_{\mathrm{T}}^{\mathrm{A}} m(a) e^{-\theta a} \mathrm{~d} a \\
\frac{\mu(\mathrm{T}+4)^{\eta}}{\eta \kappa} \int_{\mathrm{T}}^{\mathrm{A}} m(z) e^{-\gamma z} \mathrm{~d} z=1 \quad \text { with } \quad \kappa=\int_{0}^{\mathrm{A}} m(a) e^{-n a} \mathrm{~d} a .
\end{gathered}
$$




\section{Estimation of the Survival Law}

We now estimate the survival function (1) for the eight periods available for Geneva and the four periods available for Venice. The parameters $\beta$ and $\alpha$ are plotted with their confidence interval in Figure 3. From this figure we first conclude that the survival laws in Geneva and Venice are very close to each other and the parameters change at the same time in both cities. Second, considering the estimates for Geneva, we observe that there are only three significantly different laws corresponding to the periods 1625-1674, 1675-1724 and 1725-1825.

We thus assume that there are only two shifts in the parameters of the survival law. Table 2 reports these estimates and the corresponding values of the maximum age and life expectancy, which were computed from (2) and (3), respectively. To run our simulations, we have assumed that changes in the parameters of the survival law were linear and took 25 years, from 1663 to 1688 and from 1713 to 1738 .

\section{Calibration and Simulation}

The psychological discount parameter $\theta$ is set to a standard value of 0.04 . Parameters $\mu$ and $\eta$ are jointly set such that before 1663, when demographic changes started, the economy was on a balanced growth path, with GDP per capita growing at $0.1 \%$, corresponding to Maddison (1982)'s estimations for the period $1500-1700$, and with entry into the labor market at age 13 , which correspond to $\mathrm{T}(t)=3$. Accordingly, $\mu=0.2$ and $\eta=0.4$. Note that $\eta$ is the elasticity of wages to investment in education. A value of 0.4 is moderately below the 0.6 found by Heckman (1976) in contemporaneous America.
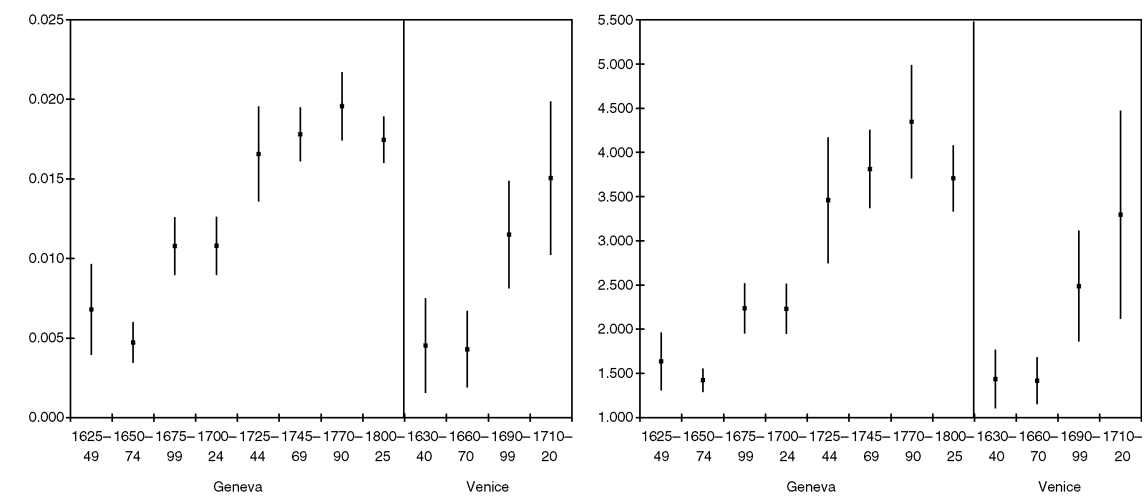

Fig. 3. Confidence intervals for the parameters $\beta$ and $\alpha$ of the survival laws 
Table 2. Estimation of Geneva's survival law

\begin{tabular}{lccc}
\hline & $1625-1674$ & $1675-1724$ & $1725-1825$ \\
\hline$\alpha$ & 1.455 & 2.178 & 3.859 \\
$\beta$ & 0.0050 & 0.0103 & 0.0179 \\
Life Exp. at 10 & 49.83 & 52.57 & 56.00 \\
Max. Age & 84.97 & 85.45 & 85.50 \\
\hline
\end{tabular}

We ran our simulations under the assumption that the survival probabilities were constant and the economy was on its balanced growth path from 1500 to 1663 , when the first demographic shock began. Under this assumption, we used (21) and (22) to compute the balanced growth path solution for $T$ and $\gamma$ for this period. A series for $\mathrm{T}(\mathrm{t})$, from 1630 to 1820 , was computed from equation (13). The effect of the mortality decline on education is displayed in Table 3. The model predicts that optimal schooling should have increased by half a year.

Next, aggregate human capital was computed from (20), for 1663-1820, using the series for $\mathrm{T}(t), \mathrm{A}(t)$ and $P(t)$ generated in the previous steps. Since the economy was on a balanced growth path until 1662, initial conditions for aggregate human capital are given by $H(t)=H e^{\gamma t}$. The constant $H$ was set to unity without any loss of generality. Table 4 displays the simulated average growth rates of both population and GDP. The transitory increase in the annual growth rate of population above $0.2 \%$ is due to the improvement in longevity. The growth rate of GDP per capita moves from the initial $0.1 \%$ to $0.14 \%$ and then to $0.19 \%$ over the period $1750-1820$. This acceleration in growth is thus estimated to $0.09 \%$ per year.

Averaging over the years $1700-1820$, we obtain a population growth of $0.3 \%$ and a GDP per capita growth of $0.17 \%$. These numbers can be compared to the estimation by Maddison in Table 1 of $0.4 \%$ and $0.2 \%$, respectively. The two shifts of the survival law can thus account for half the acceleration in population growth, while the rest is due to changes in fertility and/or infant mortality that we have not modeled here. Moreover, the early improvements in longevity account for $70 \%$ of the acceleration in growth over the period $1700-1820$.

Table 3. Age of entry on the labor market

\begin{tabular}{cccc}
\hline & $1625-1674$ & $1675-1724$ & $1725-1825$ \\
\hline $10+\mathrm{T}$ & 13 & 13.2 & 13.57 \\
\hline
\end{tabular}

(C) The editors of the Scandinavian Journal of Economics 2003. 
Table 4. Simulated growth

\begin{tabular}{lccc}
\hline & $1500-1700$ & $1700-1750$ & $1750-1820$ \\
\hline Population & 0.20 & 0.33 & 0.28 \\
GDP & 0.30 & 0.47 & 0.47 \\
GDP per capita & 0.10 & 0.14 & 0.19 \\
\hline
\end{tabular}

Note that the entire $70 \%$ is not due to the increase in schooling. Part of it simply reflects an "activity rate" effect: a drop in adult mortality increases the share of economically active persons in society, which is favorable for growth of output per capita. To evaluate the importance of this "composition" effect compared to the effect passing through human capital, we simulated the effect of changes in mortality on growth assuming a constant $\mathrm{T}(t)$; the results are that $28 \%$ of the acceleration in growth are accounted for by improvement in mortality when schooling is constant. The remaining $42 \%$ are thus related to a stronger accumulation of human capital.

\section{Sensitivity Experiments}

It remains to assess the robustness of our predictions to changes in the values of the parameters. We focus on the productivity parameters $\eta$ and $\mu$ which are crucial in the determination of the optimal schooling time and the long-term growth rate. More precisely, we vary $\eta$ from 0.3 to 0.7 and adjust the value of $\mu$ at each $\eta$ value in order to keep GDP per capita growing at $0.1 \%$ initially. The results are given in Table 5 .

In the worst case, $\eta=0.3$, the observed decline in adult mortality accounts for $45 \%$ of actual growth in the period $1700-1820$. In such a case, actual schooling time amounts to five years, to be compared with the seven-year schooling period in our reference parameterization. For high $\eta$ values, when human capital formation becomes more and more elastic with respect to schooling time, the predicted growth rates exceed the actual rate. In all cases, the observed changes in adult mortality appear as a fundamental determinant of the growth process at that time.

Table 5. Sensitivity results

\begin{tabular}{llllll}
\hline$\eta$ & 0.3 & 0.4 & 0.5 & 0.6 & 0.7 \\
$\mu$ & 0.19 & 0.20 & 0.20 & 0.18 & 0.16 \\
$\mathrm{~T}(1600)$ & 1.3 & 3 & 4.6 & 6.2 & 7.8 \\
Growth 1700-1820 & $0.145 \%$ & $0.17 \%$ & $0.19 \%$ & $0.21 \%$ & $0.23 \%$ \\
\% explained & $45 \%$ & $70 \%$ & $91 \%$ & $111 \%$ & $128 \%$ \\
\hline
\end{tabular}


A further question is whether the parameter $\eta$ can be considered constant over the period, given that the return on education is higher in cities, and that the urbanization ratio may have increased. According to Bairoch (1991), the urbanization ratio remained stationary over 1700-1800, then increased sharply. For example, defining cities as entities with 5,000 or more inhabitants, the urbanization ratio of Europe (without Russia) was $12.3 \%$ in $1700,12.1 \%$ in 1800 and $18.9 \%$ in 1850 .

As far as the structure of our model is concerned, we have abstracted from a number of features which, if incorporated into the model, would lead to an even stronger effect of mortality decline on growth. Specifically, the model assumes risk-neutral households and complete markets. The model therefore only captures decreases in expected death probabilities, while changes in the variance of those probabilities do not play a role. Typically, mortality decline also reduces uncertainty over the remaining life span and, in a model with risk-averse agents, this reduction in uncertainty tends to increase the incentive to invest in human capital even more. By abstracting from this possibility and concentrating on the increased return to education due lower death probabilities, the model therefore delivers very conservative estimates of the effect of mortality decline on education.

The effect of education on growth is model specific to the extent it depends on the presence of the externality leading to endogenous growth. As we have already stressed, the form of the externality, human capital or output, does not matter in our framework. Needless to say, if we assumed no externality, the model would be unable to capture the acceleration in long-term growth using transitional dynamics only.

\section{Conclusion}

Improvements in adult mortality and in literacy began well before the Industrial Revolution, as reported by historians. Using available survival laws for the seventeenth and eighteenth centuries, we show that life expectancy at age 10 increased by six or seven years over the period. The increase in life expectancy should have induced a rise in education, reflected in the observed increase in literacy. Moreover, this improvement in human capital should have pushed up the growth rate at the dawn of the Industrial Revolution, as reported by Maddison (1982).

In this paper, we propose an overlapping generations model where life expectancy positively affects the accumulation of human capital and growth, and use it to evaluate quantitatively the effects on growth of the observed increase in survival probabilities of adults. The parameters determining life expectancy were calibrated to replicate Geneva and Venice's survival laws over the period 1625-1825. The other parameters of the 
model were calibrated assuming that the economy is on a balanced growth path consistent with Maddison's observations for Europe over the period $1500-1700$.

The main finding is that the observed changes in adult mortality from the last quarter of the seventeenth century to the first quarter of the eighteenth century played a fundamental role in launching modern growth. In our reference parameterization with a schooling time of seven years, the decline in adult mortality induced an increase in the growth rate of around $70 \%$ of the increase estimated by Maddison. Our study thus promotes the view that the early decline in adult mortality is responsible for a large part of the acceleration of growth at the dawn of the modern age.

The next question on the agenda is twofold. First, it should be important to evaluate to what extent a higher literacy rate was a necessary condition for developing and adopting new technologies, thereby paving the way for the Industrial Revolution. For example, the growth of clockmaking and the manufacturing of precision instruments relied on a growing supply of literate craftsman. ${ }^{4}$ Second, the feedback from growth to mortality occurring in the nineteenth and twentieth centuries should be analyzed in an endogenous growth model where health expenditures allow for a reduction in mortality rates.

\section{References}

Bairoch, P. (1991), Cities and Economic Development: From the Dawn of History to the Present, University of Chicago Press, Chicago.

Beltrami, D. (1951), Lineamenti di storia della popolazione di Venezia nei secoli XVI, XVII e XVIII, Atti dell'Istituto Veneto di Scienze, Lettere ed Arti 109.

Boucekkine, R., de la Croix, D. and Licandro, O. (2002), Vintage Human Capital, Demographic Trends and Endogenous Growth, Journal of Economic Theory 104, 340-375.

Chartier, R., Compère, M.-M. and Julia, D (1976), L'éducation en France du XVI au XVIII siècle, Sedes, Paris.

Cipolla, C. (1969), Literacy and Development in the West, Penguin Books, Baltimore.

Clark, G. (2002), The Agricultural Revolution and the Industrial Revolution: England, 1500-1912, Mimeo, University of California, Davis.

Crafts, N. (1994), The Industrial Revolution, in R. Floud and D. McCloskey (eds.), The Economic History of Britain since 1700, Cambridge University Press, Cambridge.

de la Croix, D. and Licandro, O. (1999), Life Expectancy and Endogenous Growth, Economics Letters 65 (2), 255-263.

${ }^{4}$ In Geneva, well-known for the clockmaking trade, apprenticeship contracts generally included the obligation to learn how to read and write during the first year.

(C) The editors of the Scandinavian Journal of Economics 2003. 
Doepke, M. (1999), The Demographic Transition, Income Distribution and the Transition from Agriculture to Industry, Mimeo, University of California, Los Angeles.

Fleury, M. and Valmary, P. (1957), Les progrès de l'instruction élémentaire de Louis XIV à Napoléon III, d'après l'enquète de Louis Maggiolo 1877-1879, Population, 71-92.

Fridlizius, G. (1985), The Mortality Decline in the First Phase of the Demographic Transition: Swedish Experiences, in T. Bengtsson, G. Fridlizius and R. Ohlsson (eds.), Pre-industrial Population Change, Almquist \& Wiksell International, Stockholm, 71-114.

Galor, O. and Weil, D. (2000), Population, Technology, and Growth: From the Malthusian Regime to the Demographic Transition and Beyond, American Economic Review 90 (4), 806-828.

Hansen, G. and Prescott, E. (1998), Malthus to Solow, NBER Working Paper no. 6858.

Heckman, J. (1976), A Life-cycle Model of Earnings, Learning, and Consumption, Journal of Political Economy 84 (4), S11-S44.

Jones, C. (2001), Was an Industrial Revolution Inevitable? Economic Growth over the Very Long-run, Mimeo, Stanford University.

Kalemli-Ozcan, S., Ryder, H. and Weil, D. (2000), Mortality Decline, Human Capital Investment, and Economic Growth, Journal of Development Economics 62 (1), 1-23.

Maddison, A. (1982), Phases of Capitalist Development, Oxford University Press, Oxford.

Maddison, A. (2001), The World Economy-A Millennial Perspective, Development Centre Studies, OECD, Paris.

Marczewski, J. (1961), Some Aspects of Economic Growth of France, 1660-1958, Economic Development and Cultural Change 9, 369-396.

Perrenoud, A. (1978), La mortalité à Genève de 1625 à 1825, Annales de démographie historique, 209-233.

Perrenoud, A. (1985), Mortality Decline in its Secular Setting, in T. Bengtsson, G. Fridlizius and R. Ohlsson (eds.), Pre-industrial Population Change, Almquist \& Wiksell International, Stockholm, 41-69.

Riley, J. (2001), Rising Life Expectancy: A Global History, Cambridge University Press, Cambridge.

Rostow, W. (1960), The Stages of Economic Growth, Cambridge University Press, New York.

Schama, S. (1977), Patriots and Liberators. Revolution in the Netherlands, 1780-1813, Collins, London.

Stokey, N. (2001), A Quantitative Model of the British Industrial Revolution, 1780-1850, Carnegie-Rochester Conference Series on Public Policy 55, 55-109.

Stone, L. (1969), Literacy and Education in England 1640-1900, Past and Present 42, 69-139.

Vallin, J. (1991), Mortality in Europe from 1720 to 1914-Long-term Trends and Changes in Patterns by Age and Sex, in R. Schofield, D. Reher and A. Bideau (eds.), The Decline in Mortality in Europe, Oxford University Press, Oxford.

Wrigley, E. and Schofield, R. (1981), The Population History of England, 1541-1871: A Reconstruction, Harvard University Press, Cambridge, MA. 